Published in final edited form as:

J Am Coll Surg. 2017 April ; 224(4): 740-748. doi:10.1016/j.jamcollsurg.2016.12.014.

\title{
Management of Immediate Post-Endovascular Aortic Aneurysm Repair Type la Endoleaks and Late Outcomes
}

\author{
Ali F AbuRahma, MD, FACS, \\ Department of Surgery, West Virginia University, Charleston, WV \\ Stephen M Hass, MD, FACS, \\ Stone), Charleston, WV \\ Zachary T AbuRahma, DO, \\ Department of Surgery, West Virginia University, Charleston, WV \\ Michael Yacoub, MD, \\ Department of Surgery, West Virginia University, Charleston, WV \\ Albeir Y Mousa, MD, FACS, \\ Department of Surgery, West Virginia University, Charleston, WV \\ Shadi Abu-Halimah, MD, FACS, \\ Department of Surgery, West Virginia University, Charleston, WV \\ L Scott Dean, PhD, MBA, and \\ CAMC Health Education and Research Institute, Charleston, WV \\ Patrick A Stone, MD, FACS \\ Department of Surgery, West Virginia University, Charleston, WV
}

Department of Surgery, West Virginia University (Z AbuRahma, Yacoub, Mousa, Abu-Halimah,

\begin{abstract}
BACKGROUND—Post-endovascular aortic aneurysm repair (EVAR) endoleaks and the need for reintervention are challenging. Additional endovascular treatment is advised for type Ia endoleaks detected on post-EVAR completion angiogram. This study analyzed management and late outcomes of these endoleaks.
\end{abstract}

\footnotetext{
Correspondence address: Ali F AbuRahma, MD, FACS, Department of Surgery, West Virginia University, 3110 MacCorkle Ave, SE, Charleston, WV 25304. ali.aburahma@camc.org.

Author Contributions

Study conception and design: A AbuRahma, Hass, Z AbuRahma, Yacoub, Mousa, Abu-Halimah, Dean, Stone

Acquisition of data: A AbuRahma, Hass, Z AbuRahma, Yacoub, Mousa, Abu-Halimah, Dean, Stone

Analysis and interpretation of data: A AbuRahma, Hass, Z AbuRahma, Dean

Drafting of manuscript: A AbuRahma, Hass, Z AbuRahma

Critical revision: A AbuRahma, Hass, Z AbuRahma, Dean

CME questions for this article available at http://jacscme.facs.org

Disclosure Information: Authors have nothing to disclose. Timothy J Eberlein, Editor-in-Chief, has nothing to disclose.

Presented at the Southern Surgical Association 128th Annual Meeting, Palm Beach, FL, December 2016.
} 
STUDY DESIGN-This was a retrospective review of prospectively collected data from EVAR patients during a 10-year period. All post-EVAR type Ia endoleaks on completion angiogram were identified (group A) and their early (30-day) and late outcomes were compared with outcomes of patients without endoleaks (group B). Kaplan-Meier analysis was used for survival analysis, sac expansion, late type Ia endoleak, and reintervention.

RESULTS-Seventy-one of 565 (12.6\%) patients had immediate post-EVAR type Ia endoleak. Early intervention (proximal aortic cuffs and/or stenting) was used in 56 of $71(79 \%)$ in group A vs 31 of $494(6 \%)$ in group B (p < 0.0001). Late type Ia endoleak was noted in 9 patients $(13 \%)$ in group A at a mean follow-up of 28 months vs 10 patients (2\%) in group B at a mean follow-up of 32 months ( $\mathrm{p}<0.0001)$. Late sac expansion and reintervention rates were $9 \%$ and $10 \%$ for group A vs $5 \%$ and $3 \%$ for group B $(p=0.2698$ and $p=0.0198)$, respectively. Freedom rates from late type Ia endoleaks at 1, 3, and 5 years for group A were $88 \%, 85 \%$, and $80 \%$ vs $98 \%, 98 \%$, and $96 \%$ for group B ( $<<0.001$ ); and for late intervention, were $94 \%, 92 \%$, and $77 \%$ for group A, and $99 \%, 97 \%$, and $95 \%$ for group B ( $\mathrm{p}=0.007)$, respectively. Survival rates were similar.

CONCLUSIONS-Immediate post-EVAR type Ia endoleaks are associated with higher rates of early interventions, late endoleaks and reintervention, which will necessitate strict post-EVAR surveillance.

After endovascular aortic aneurysm repair (EVAR), patients may experience various complications, including endoleaks, device migration, graft deterioration/fractures, or aneurysm expansion that may require reintervention. Type I endoleak is defined as continued flow into the aneurysmal sac at the proximal attachment sites of the endograft to the native aorta or at the iliac artery wall distally, and is generally referred to as type Ia and type $\mathrm{Ib}$ endoleaks, respectively. ${ }^{1}$ These attachment site endoleaks have been demonstrated on postEVAR angiography in approximately $7 \%$ of patients. ${ }^{2}$ They usually prompt immediate treatment using proximal and/or distal extender modules, percutaneous transluminal angioplasty/stenting, or coil embolization. ${ }^{3,4}$ Also, an estimated $10 \%$ of patients who undergo EVAR may develop type I endoleaks at some time during follow-up. ${ }^{5}$

Failure to exclude abdominal aortic aneurysms (AAA) from continued perfusion (endoleak) and sac pressurization remains a serious challenge for EVAR ${ }^{6-9}$ Additional endovascular therapy is generally advised for type Ia endoleaks detected on post-EVAR completion angiograms. Few studies have discussed the significance and management of these type Ia endoleaks. This analyzed the incidence, management, and late outcomes of these endoleaks.

\section{METHODS}

This is a retrospective review of prospectively collected data on 565 patients who underwent elective endovascular infrarenal aortic aneurysm repair (EVAR) at our medical center during a 10-year period. The devices used included AneuRx, Talent, and Endurant (Medtronic Corporation); Excluder (WL Gore and Associates); Zenith (Cook Corporation); and Powerlink (Endologix). Patients who lacked good quality preoperative CT scanning were excluded. 
All procedures were performed under general or epidural anesthesia using a modern imaging system (General Electric Medical). Patients were advised to participate in postoperative surveillance protocol, which included CT angiography (CTA) or color duplex ultrasound within 30 days of the procedure, and if normal (no evidence of endoleak or other abnormalities), a color duplex ultrasound was repeated at 6 months, 12 months, and every 12 months thereafter. A CTA was obtained only if there was evidence of sac enlargement and/or endoleak by color duplex ultrasound.

Demographic and clinical characteristics of these patients were analyzed. All intraoperative data, including the presence of type Ia endoleaks at post-EVAR completion angiography and their treatment, 30-day postoperative adverse events, and late events were analyzed. This study was approved by the Institutional Review Board of Charleston Area Medical Center/ West Virginia University and informed consent was not required.

\section{Definitions and primary endpoints}

Every effort was made to follow the recommendations of the Ad Hoc Committee of the Stent Graft Standardized Reporting Practice in Vascular Surgery. ${ }^{10}$ Endoleak was determined using CT scanning if extravasation of contrast between the prosthesis and the aneurysm wall was noted or by color duplex ultrasound where the color flow and Doppler spectral signal were outside the prosthesis, or both. If the duplex ultrasound and CT results differed, conventional contrast arteriography was done to confirm the endoleak. The term "early endoleak" was used for a leak detected intraoperatively on completion angiography or less than 30 days postoperatively, and a "late endoleak" was defined as a leak discovered 30 days or more postoperatively. Significant AAA sac expansion was defined as an increase of $\geq 5 \mathrm{~mm}$ in sac size (compared with preoperative sac size), and significant shrinkage was defined as a decrease of $25 \mathrm{~mm}$ from the preoperative size. The term "migration" was determined by measuring the distance from lowest renal artery and the most cephalad part of the stent graft based on CT images. Significant migration was referred to as displacement requiring secondary intervention or displacement of $\geq 10 \mathrm{~mm}$ from the previous study.

The primary endpoint included early 30-day perioperative outcomes: rate of early endoleak (specifically, proximal type Ia) and the rate of early intervention, including the use of proximal aortic neck cuffs or proximal aortic stents to seal proximal aortic endoleak. Late clinical outcomes included late type Ia endoleaks, aortic sac expansion, late reintervention to treat endoleak or other complications, stent migration, conversion to open repair, and late mortality (aneurysm-related deaths). All deaths were verified using the Social Security Death Index.

\section{Statistical methods}

Data were analyzed using SAS 9.1. Comparisons were performed between patients with type Ia endoleak at post-completion EVAR angiography (group A) vs patients without endoleak (group B), using contingency table analysis with a chi-square or Fisher's exact test (categorical variables) and $t$-tests (continuous variables) to determine statistically significant differences. The Kaplan-Meier method was used to compare rates of freedom from late type 
Ia endoleak, late intervention, sac expansion, and survival for both groups. Comparisons were based on the log-rank test.

\section{RESULTS}

Five hundred sixty-five patients were analyzed, and 71 of these had type Ia endoleak (12.6\%; group A) on immediate post-completion EVAR angiography; 494 patients had none

(87.4\%; group B). Demographic and clinical characteristics of these patients are summarized in Table 1. As noted, there were no significant differences between both groups except for age.

\section{Early intervention}

Early intervention (use of proximal aortic cuffs or proximal aortic Palmaz stenting) was done in 56 of 71 patients (79\%) in group A, vs 31 of 494 patients (6\%) in group B (p < 0.0001). The early intervention in group A included 5 proximal aortic Palmaz stents, 45 aortic cuff extensions, and 6 patients had both aortic cuff extensions and Palmaz stents. The 15 remaining patients in group A, who had no early intervention, were either treated with percutaneous transluminal angioplasty of the proximal aortic attachment site alone or were believed to have minimal proximal type Ia endoleak, which did not justify early intervention. Thirty-one patients in group B had early intervention (proximal aortic cuffs and/or aortic stents) for type Ia endoleaks, which were detected on the postoperative CTA and/or color duplex ultrasound that was done within 30 days, but were not present on the immediate postcompletion angiograms.

\section{Late clinical outcomes}

Late type Ia endoleak was noted in 9 patients (13\%) in group A at a mean follow-up of 28 months vs 10 patients $(2 \%)$ in group B at a mean follow-up of 32 months $(\mathrm{p}<0.0001)$. Late sac expansion and reintervention rates were $9 \%$ and $10 \%$ for group A vs $5 \%$ and $3 \%$ for group B ( $p=0.2698$ and $p=0.0198)$, respectively (Table 2$)$. As noted, there were significant differences between late type Ia endoleak and late intervention between groups A and B. All patients with late type Ia endoleaks ( 9 patients) in group A had initial early post-EVAR type Ia endoleaks on completion angiograms, in contrast to 10 of 31 with late type Ia endoleaks in group B, who had early interventions for early endoleaks.

Overall, 7 of 68 patients in group A had late intervention: 3 due to sac expansion and 4 due to late type Ia endoleak. It should be noted that 1 patient had both late type Ia endoleak and sac expansion. Three patients in group A had no late outcomes beyond 30 days. These late interventions included placing another proximal aortic cuff in 3 patients, an aortic unilateral device with a femorofemoral bypass graft in 1 patient, a fenestrated EVAR in 2 patients, and 1 patient was transferred, based on his request, to Cleveland Clinic, where he underwent further repair. Overall, there were 10 of 68 (15\%) late deaths in group A vs 45 of 458 (10\%) in group B $(p=0.2197)$. None of these late deaths were related to AAA rupture. 


\section{Kaplan-Meier analysis of late type la endoleak, late intervention, sac expansion, and survival}

Freedom rates from late type Ia endoleaks at 1,3 , and 5 years for group A were significantly lower: $88 \%, 85 \%$, and $80 \%$ vs 98\%, 98\%, and 96\%, respectively, for group B ( $\mathrm{p}<0.001$; Fig. 1); and for late intervention, $94 \%, 92 \%$, and $77 \%$ for group A vs $99 \%, 97 \%$, and $95 \%$ for group B ( $\mathrm{p}=0.007)$, respectively (Fig. 2). The freedom rates from sac expansion at 1,3 , and 5 years for group A were $97 \%, 86 \%$, and $81 \%$, vs $98 \%, 92 \%$, and $87 \%$ for group B, respectively ( $\mathrm{p}=0.373$; Fig. 3 ). Figure 4 summarizes survival rates for both groups, which were similar.

\section{DISCUSSION}

In the modern era, endovascular management has become the standard treatment for infrarenal AAA, with up to $70 \%$ of them repaired by endovascular stent graft placement in the United States. ${ }^{11}$ Although EVAR has demonstrated better short-term and mid-term outcomes than open AAA treatment, ${ }^{12,13}$ as well as comparable long-term survival, ${ }^{14}$ up to $15 \%$ to $20 \%$ of patients require a secondary intervention. ${ }^{15}$ One of the most troubling reasons for a secondary intervention is an endoleak, which can account for up to roughly $57 \%$ of all reinterventions. ${ }^{16}$ Of all types of endoleaks, a type I endoleak is the most worrisome, and traditional teaching mandates immediate repair of this type of endoleak. ${ }^{16,17}$ A type Ia endoleak involves the proximal seal; a type Ib endoleak involves the distal seal.

A type Ia endoleak is commonly discovered with the completion angiogram demonstrating contrast extravasation into the aneurysm sac, originating at or near the proximal seal zone. Because of the potential deleterious effects of this leak that can occur if left untreated, a variety of intraoperative adjunctive measures can be performed, such as balloon angioplasty of the proximal attachment site, proximal device extension, deployment of a large bare metal stent, embolization, or placement of endovascular screws. ${ }^{18-20}$ Others have advocated the chimney technique and fenestrated extension. ${ }^{21,22}$

Buth and colleagues ${ }^{23}$ reported the results of data collected in the EUROSTAR database from 110 European centers, and they noted that type I and type III endoleaks were associated with an increased frequency of open conversion or risk of aneurysm rupture. They also reported that 15 patients experienced aneurysm rupture at a mean of 16 months postoperatively (range 3 to 36 months): 10 (3.4\%) patients with types I/III endoleak and 5 $(0.25 \%)$ without endoleaks. The cumulative rate of AAA rupture in patients with endoleak was $4 \%$ at 2 years and was significantly higher than in patients without endoleak $(0.7 \% ; \mathrm{p}=$ 0.0001). They believed that these endoleaks need to be treated without delay by endovascular means or by open repair.

In another study, Antoniou and associate ${ }^{24}$ conducted a systematic review and metaanalysis of late rupture of AAAs after a previous EVAR and reported that 15 ruptures occurred after 16,974 EVAR procedures in 8 of the case series, with an incidence of $0.9 \%$. The mean time to rupture was 37 months, and the predominant reasons for rupture were type I and III endoleaks. Of patients who underwent treatment, $61 \%$ had open surgery. They concluded that graft-related endoleaks appeared to be the predominant cause of late 
aneurysm rupture. Antonopoulos and coworkers ${ }^{25}$ also reported on 22 patients with ruptured AAAs after previous EVAR, who presented to 7 referral hospitals in Greece; type Ia endoleak and endograft migration were identified in $72.7 \%$ and $50 \%$, respectively. They concluded that type I endoleak and endograft migration were most frequently observed, and compliance to follow-up was low.

Recent studies now challenge the standard dogma of immediate treatment of type I endoleaks, in particular, type Ia endoleaks, claiming that spontaneous resolution with conservation management is possible without subsequent intervention. Tan and colleagues ${ }^{14}$ evaluated more than 2,400 EVARs from the Vascular Study Group of New England database from 2003 to 2012, and they compared the outcomes of patients who had type I endoleaks at the completion of the procedure with those who did not. Eighty-eight (3.3\%) of these patients had a type I endoleak at completion, and after a 1-year follow-up period, $90 \%$ of them had resolution of the endoleak without the need for any additional endovascular or open intervention. ${ }^{14}$

Risk factors identified for the initial type I endoleak included an age greater than 70 years, female sex, unplanned intraoperative graft extension, and a larger main body graft diameter requirement. Factors that were not independently associated with an intraoperative type I endoleak included maximum aneurysm size, smoking, and grafts with suprarenal fixation, all of which have been related to type I endoleaks in other publications. ${ }^{2,26,27}$ However, due to limitations inherent in the database analyzed, this study could not evaluate patients who had type I endoleaks treated successfully, and more importantly, could not differentiate between type Ia and Ib endoleaks. One could argue the natural history of spontaneous closure of a type $\mathrm{Ib}$ endoleak, or the durability of an intervention to correct the type $\mathrm{Ib}$ endoleak may be significantly different than that of a type Ia endoleak. ${ }^{28}$

In another recent study by Millen and associates, ${ }^{29} 94 \%$ of patients with type Ia endoleaks found on completion arteriography after standard EVAR had endoleaks that resolved spontaneously. The initial completion arteriogram identified 44 of 209 patients with type Ia endoleaks, with 33 patients (75\%) having a persistent endoleak even after intraoperative adjunctive procedures were performed, which included repeat balloon angioplasty, aortic cuff extension, and Palmaz stent (Cordis) placement. ${ }^{29}$ Eleven patients had successful treatment of the type Ia endoleak during the initial EVAR procedure, and there was no evidence of recurrent endoleak in these patients during a median follow-up of 27 months. For those 33 patients with persistent type Ia endoleaks, in spite of attempts at repair during the initial EVAR procedure, 31 showed spontaneous resolution of the endoleak on the first surveillance evaluation using CTA, resulting in a 94\% spontaneous resolution. ${ }^{29}$

Other studies have reported similar results. In an evaluation of 15 patients, Bastos and colleagues $^{30}$ identified 14 patients who had spontaneous type Ia endoleak closures, with 1 patient ultimately developing a recurrent type Ia endoleak years later, and 1 patient with an unconfirmed recurrent endoleak. Kim and coworkers ${ }^{18}$ evaluated 86 patients undergoing EVAR and found spontaneous closure of type Ia endoleaks in 7 of 10 patients, although the median follow-up period was only 14 months. 
Venermo and coauthors ${ }^{31}$ reported that among 400 patients who were treated with EVAR at a single institution, 21 patients $(5.3 \%)$ with large aneurysms $(25.5 \mathrm{~cm})$ had imaging evidence of type Ia endoleaks that persisted beyond 10 months, despite secondary endovascular treatment. They compared these patients with 24 untreated AAA patients. During follow-up, the rate of aneurysm enlargement was significantly lower in patients with type Ia endoleaks $(0.19 \mathrm{~cm} /$ year $)$ than in untreated AAA patients $(0.54 \mathrm{~cm} /$ year; $\mathrm{p}=0.03)$. One patient $(4.8 \%)$ with a persisting type Ia endoleak and 2-cm aneurysm enlargement $(0.8$ $\mathrm{cm} /$ year) had aneurysm rupture after 2.5 years, while $12(50 \%)$ of the 24 untreated AAAs ruptured $(\mathrm{p}=0.001)$. They concluded that EVAR may reduce the risk of rupture and aneurysm-related death despite the presence of a persisting type Ia endoleak.

In our study, 565 standard infrarenal EVARs were analyzed. Seventy-one patients had a type Ia endoleak identified during the initial EVAR procedure on completion angiography (group A); 494 patients demonstrated no evidence of type Ia endoleak on arteriography, again assessed at the initial EVAR procedure (group B). Of those 71 patients with endoleaks, 56 underwent early interventions at the initial EVAR procedure, with placement of Palmaz stents in 5, aortic extension cuffs in 45, and a combination of both a Palmaz stent and an aortic cuff in 6 patients. Fifteen patients did not have any significant interventions other than standard compliant balloon inflation at the proximal seal zone; endoleaks discovered in these patients were deemed "minimal", and the decision was made to forego more aggressive measures in favor of conservation and close re-evaluation. During further follow-up, 9 patients continued to demonstrate "late" type Ia endoleaks persisting more than 30 days after the initial procedure. Of these 9 patients, 7 underwent late interventions: 3 patients had additional aortic cuff extensions, 1 patient underwent a combined aortounilimb placement along with a femoral-femoral bypass, and 2 patients underwent complex fenestrated graft repair. One patient chose transfer to another facility.

In group B, 494 patients did not demonstrate a type Ia endoleak on completion arteriography during the initial procedure. However, 31 patients ultimately had a type Ia endoleak discovered within 30 days of the original procedure (6\%) using color duplex ultrasound and/or CTA; all of which underwent an early intervention for treatment. Despite these interventions, "late" type Ia endoleaks were discovered in 10 of these patients.

Comparing the 2 groups, group A had a significantly higher rate of early intervention (79\% vs $6 \%$ ), development of a late type Ia endoleak (13\% vs $2 \%$ ), and need for late intervention (10\% vs 3\%). Late sac expansion rates were also somewhat higher in group A (9\% vs 5\%). There was also a distinct disadvantage for group A with regard to freedom rates from type Ia endoleaks at 1,3 , and 5 years $(88 \%, 85 \%$, and $80 \%$ vs $98 \%, 98 \%$, and $96 \%$, respectively), as well as freedom rates for late intervention $(94 \%, 92 \%$, and $77 \%$ vs $99 \%, 97 \%$, and $95 \%$, respectively).

Our results are somewhat similar to those of Sampaio and associates, ${ }^{28}$ who sought to determine the frequency and nature of intraoperative endoleaks and their impact on postoperative endoleak-related events. An endoleak was observed in 126 of 241 patients (52.3\%). Type I endoleaks were observed in 63 (26.1\%) cases: 35 type Ia and 31 type $\mathrm{Ib}(3$ patients had both). These endoleaks were treated with angioplasty, additional cuff 
placement, or stenting in $59(89.4 \%)$. They also reported that patients with a type I or II intraoperative endoleak were more often likely to have an endoleak at 1.5 years (31.4\% vs $21.6 \% ; p=0.018)$. Reinterventions were needed more often in patients with intraoperative type I endoleak ( $10 \%$ vs $4 \% ; \mathrm{p}=0.003)$. Patients with intraoperative endoleaks demonstrated a trend toward less post-operative aneurysm sac diameter reduction at 2 years (43.8\% vs $74.5 \% ; \mathrm{p}=0.104)$. They concluded that the presence of a type I or type II endoleak during EVAR significantly increases the likelihood of a postoperative endoleak and should prompt a high degree of suspicion during late follow-up.

So based on our study, identification of a type Ia endoleak at the time of the initial procedure signifies a more troublesome situation, one that requires diligent monitoring postoperatively and a higher likelihood of recurrent type Ia endoleak. The need for subsequent intervention is less if no endoleak is discovered on completion arteriography after standard EVAR, but we would, nevertheless, recommend some degree of continued postoperative surveillance to ensure these leaks do not develop at a later time.

There are a few limitations of our study. The main one lies with its retrospective design, which carries all of the inherent bias associated with patient selection and device selection (which is at the discretion of the physician). We were also limited to the data that were routinely collected and stored in electronic medical records. In addition, there was no uniformity in the method of surveillance.

\section{CONCLUSIONS}

Immediate post-EVAR type Ia endoleak is associated with higher rates of early interventions, late endoleaks, and intervention, which will necessitate stricter post-EVAR surveillance.

\section{Acknowledgments}

The authors gratefully acknowledge Mary Emmett, $\mathrm{PhD}$ for her assistance and Mona Lett for her editorial assistance in the preparation of this manuscript.

\section{Abbreviations and Acronyms}
AAA
abdominal aortic aneurysm
CTA
computed tomography angiography
EVAR
endovascular aortic aneurysm repair

\section{References}

1. Toya N, Kanaoka Y, Ohki T. Secondary interventions following endovascular repair of abdominal aortic aneurysm. Gen Thor Cardiovasc Surg. 2014; 62:87-94.

2. Mohan IV, Laheij RJ, Harris PL. Risk factors for endoleak and the evidence for stent-graft oversizing in patients undergoing endovascular aneurysm repair. Eur J Vasc Endovasc Surg. 2001; 21:344-349. [PubMed: 11359336] 
3. Chung J, Corriere MA, Milner R, et al. Midterm results of adjunctive neck therapies performed during elective infrarenal aortic aneurysm repair. J Vasc Surg. 2010; 52:1435-1441. [PubMed: 21146743]

4. Tzortzis E, Hinchliffe RJ, Hopkinson BR. Adjunctive procedures for the treatment of proximal type I endoleak: the role of peri-aortic ligatures and Palmaz stenting. J Endovasc Ther. 2003; 10:233239. [PubMed: 12877604]

5. Franks SC, Sutton AJ, Bown MJ, Sayers RD. Systematic review and meta-analysis of 12 years of endovascular abdominal aortic aneurysm repair. Eur J Vasc Endovasc Surg. 2011; 41(Suppl 1):S1S58. [PubMed: 21215940]

6. Alimi YS, Chakfe N, Rivoal E, et al. Rupture of an abdominal aortic aneurysm after endovascular graft placement and aneurysm size reduction. J Vasc Surg. 1998; 28:178-183. [PubMed: 9685144]

7. White RA, Donayre C, Walot I, et al. Abdominal aortic aneurysm rupture following endoluminal graft deployment: report of a predictable event. J Endovasc Ther. 2000; 7:257-262. [PubMed: 10958288]

8. Harris PL, Vallabhaneni SR, Desgranges P, et al. Incidence and risk factors of late rupture, conversion, and death after endovascular repair of infrarenal aortic aneurysms: the EUROSTAR experience. J Vasc Surg. 2000; 32:739-749. [PubMed: 11013038]

9. AbuRahma AF. Fate of endoleaks detected by CT angiography and missed by color duplex ultrasound in endovascular grafts for abdominal aortic aneurysms. J Endovasc Ther. 2006; 13:490_ 495. [PubMed: 16928163]

10. Chaikof EL, Blankenesteijn JD, Harris PL, et al. Reporting standards for endovascular aortic aneurysm repair. J Vasc Surg. 2002; 35:1048-1060. [PubMed: 12021727]

11. Patel VI, Lancaster RT, Mukopadhyay S, et al. Impact of chronic kidney disease on outcomes after abdominal aortic aneurysm repair. J Vasc Surg. 2012; 56:1206-1213. [PubMed: 22857808]

12. Lederle FA, Freishlag JA, Kyriakides TC, et al. Long-term comparison of endovascular and open repair of abdominal aortic aneurysm. N Engl J Med. 2012; 367:1988-1997. [PubMed: 23171095]

13. Lederle FA, Freishlag JA, Kyriakides TC, et al. Outcomes following endovascular vs open repair of abdominal aortic aneurysm: a randomized trial. JAMA. 2009; 302:1535-1542. [PubMed: 19826022]

14. Tan TW, Eslaim M, Rybin D, et al. Outcomes of patients with Type I endoleak at completion of endovascular abdominal aneurysm repair. J Vasc Surg. 2016; 63:1420-1427. [PubMed: 27038837]

15. Pitoulias GA, Schulte S, Donas KP, Horsch S. Secondary endovascular and conversion procedures for failed endovascular abdominal aortic aneurysm repair: Can we still be optimistic? Vascular. 2009; 17:15-22. [PubMed: 19344578]

16. Mehta M, Sternbach Y, Taggert JB, et al. Long-term outcomes of secondary procedures after endovascular aneurysm repair. J Vasc Surg. 2010; 52:1442-1449. [PubMed: 20724099]

17. Veith FJ, Baum RA, Ohki T, et al. Nature and significance of endoleaks and endotension: Summary of opinions expressed at an international conference. J Vasc Surg. 2002; 35:1029-1035. [PubMed: 12021724]

18. Kim SM, Ra HD, Min S, et al. Clinical significance of Type I endoleak on completion angiography. Ann SurgTreat Res. 2014; 86:95-99.

19. Brownrigg JR, de Bruin JL, Rossi L, et al. Endovascular aneurysm sealing for infrarenal abdominal aortic aneurysms: 30-day outcomes of 105 patients in a single centre. Eur J Vasc Endovasc Surg. 2015; 50:157-164. [PubMed: 25892319]

20. Donselaar EJ, van der Vijver-Coppen RJ, van den Ham LH, et al. EndoAnchors to resolve persistent Type Ia endoleak secondary to proximal cuff with parallel graft placement. J Endovasc Ther. 2016; 23:225-228. [PubMed: 26668128]

21. Montelione N, Pecoraro F, Puippe G, et al. A 12-year experience with chimney and periscope grafts for treatment of Type I endoleaks. J Endovasc Ther. 2015; 22:568-574. [PubMed: 25969150]

22. Ronchey S, Serrao E, Kasemi H, et al. Endovascular treatment options for complex abdominal aortic aneurysms. J Vasc Intervent Rad. 2015; 26:842-854.

23. Buth J, Harris PL, van Marrewijk C, et al. The significance and management of different types of endoleaks. Semin Vasc Surg. 2003; 16:95-102. [PubMed: 12920679] 
24. Antoniou GA, Georgiadis GS, Antoniou SA, et al. Late rupture of abdominal aortic aneurysms after previous endovascular repair: A systematic review and meta-analysis. J Endovasc Ther. 2015; 22:734-744. [PubMed: 26286073]

25. Antonopoulos CN, Kakisis JD, Giannakopoulos TG, et al. Rupture after endovascular abdominal aortic aneurysm repair: a multicenter study. Vasc Endovascular Surg. 2014; 48:476-481. [PubMed: 25480667]

26. Bastos GF, Hoeks SE, Teijink JA, et al. Risk factors for proximal neck complications after endovascular aneurysm repair using the Endurant stent graft. Eur J Vasc Endovasc Surg. 2015; 49:156-162. [PubMed: 25458435]

27. Hager ES, Cho JS, Makaroun MS, et al. Endografts with suprarenal fixation do not perform better than those with infrarenal fixation in the treatment of patients with short straight proximal aortic necks. J Vasc Surg. 2012; 55:1242-1246. [PubMed: 22277692]

28. Sampaio SM, Shin SH, Panneton JM, et al. Intraoperative endoleak during EVAR: frequency, nature, and significance. Vasc Endovasc Surg. 2009; 43:352-359.

29. Millen AM, Osman K, Antoniou GA, et al. Outcomes of persistent intraoperative type Ia endoleak after standard endovascular aneurysm repair. J Vasc Surg. 2015; 61:1185-1191. [PubMed: 25656591]

30. Bastos GF, Verhagen HJM, Vasanthananthan K, et al. Spontaneous delayed sealing in selected patients with a primary Type Ia endoleak after endovascular aneurysm repair. Eur J Vasc Endovasc Surg. 2014; 48:53-59. [PubMed: 24581938]

31. Venermo MA, Arko FR III, Salenius JP, et al. EVAR may reduce the risk of aneurysm rupture despite persisting type Ia endoleaks. J Endovasc Ther. 2011; 18:676-682. [PubMed: 21992639] 


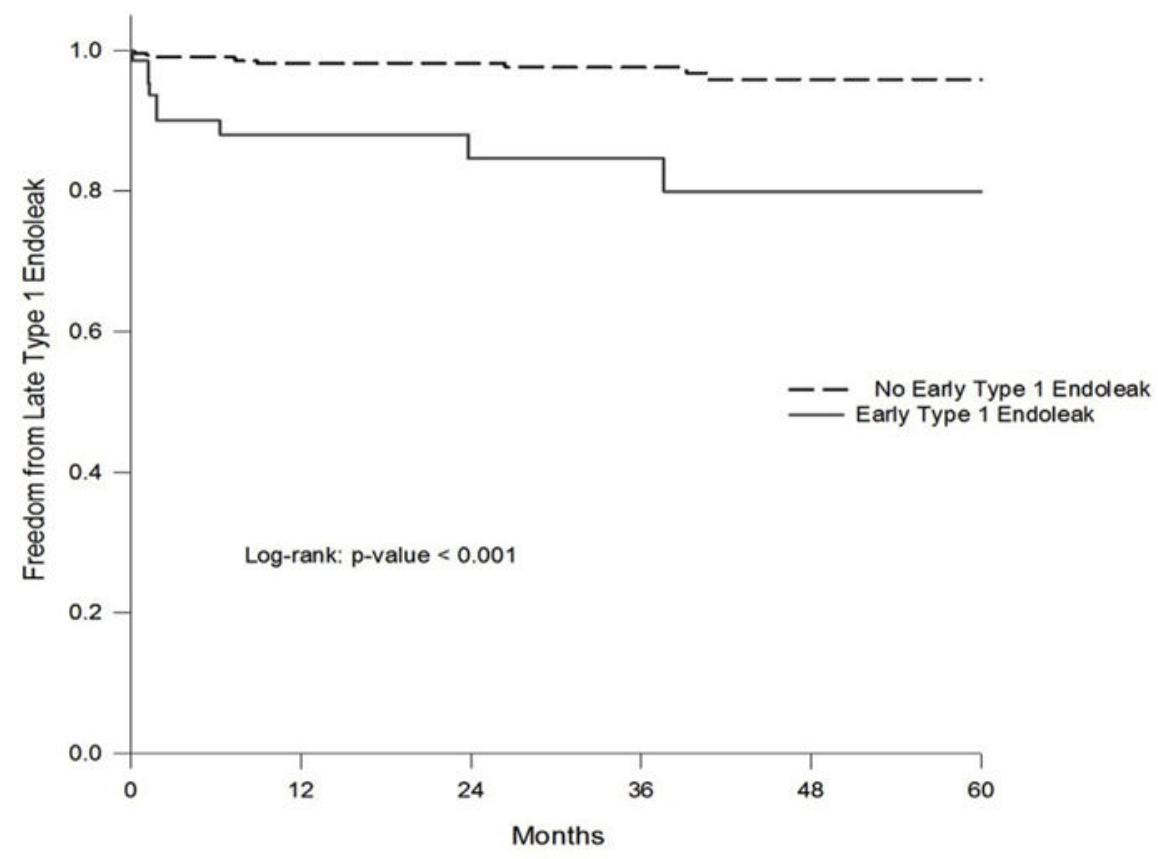

\begin{tabular}{|l|c|c|c|c|c|c|}
\hline \multirow{2}{*}{ Months } & \multicolumn{3}{|c|}{ Early type Ia endoleak (group A) } & \multicolumn{3}{c|}{ No early type Ia endoleak (group B) } \\
\cline { 2 - 7 } & At risk, n & \% & SE & At risk, n & $\%$ & SE \\
\hline 12 & 41 & 88.1 & 4.27 & 297 & 98.2 & 0.69 \\
\hline 24 & 25 & 84.7 & 5.28 & 191 & 98.2 & 0.69 \\
\hline 36 & 17 & 84.7 & 5.28 & 126 & 97.6 & 0.89 \\
\hline 48 & 13 & 80 & 6.76 & 84 & 95.9 & 1.49 \\
\hline 60 & 8 & 80 & 6.76 & 55 & 95.9 & 1.49 \\
\hline
\end{tabular}

Figure 1.

Freedom from late type Ia endoleak for groups A and B. 


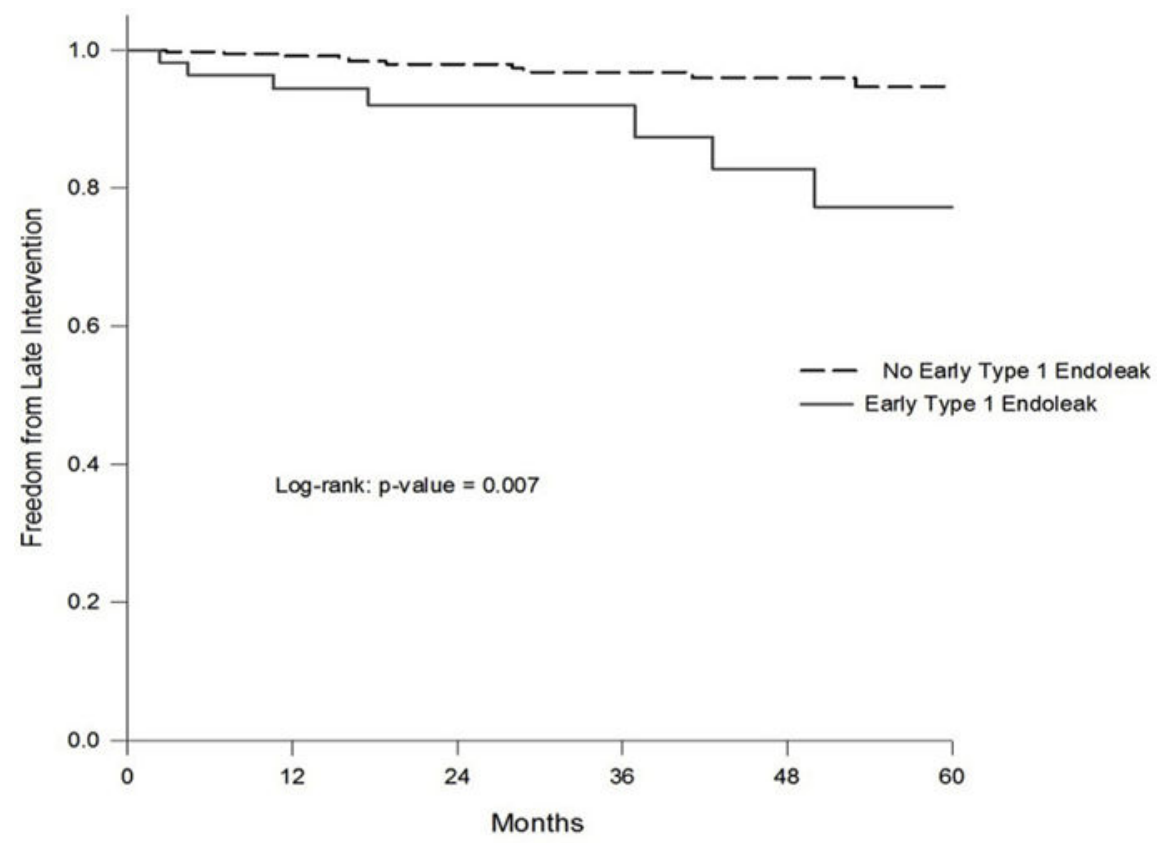

\begin{tabular}{|l|c|c|c|c|c|c|}
\hline \multirow{2}{*}{ Months } & \multicolumn{3}{|c|}{ Early type Ia endoleak (group A) } & \multicolumn{3}{c|}{ No early type Ia endoleak (group B) } \\
\cline { 2 - 7 } & At risk, n & $\%$ & SE & At risk, n & $\%$ & SE \\
\hline 12 & 46 & 94.4 & 3.14 & 304 & 99.1 & 0.5 \\
\hline 24 & 27 & 92 & 3.88 & 194 & 98 & 0.84 \\
\hline 36 & 21 & 92 & 3.88 & 129 & 96.8 & 1.18 \\
\hline 48 & 15 & 82.8 & 7.09 & 89 & 95.9 & 1.44 \\
\hline 60 & 9 & 77.3 & 8.5 & 57 & 94.6 & 1.91 \\
\hline
\end{tabular}

Figure 2.

Freedom from late intervention for groups A and B. 


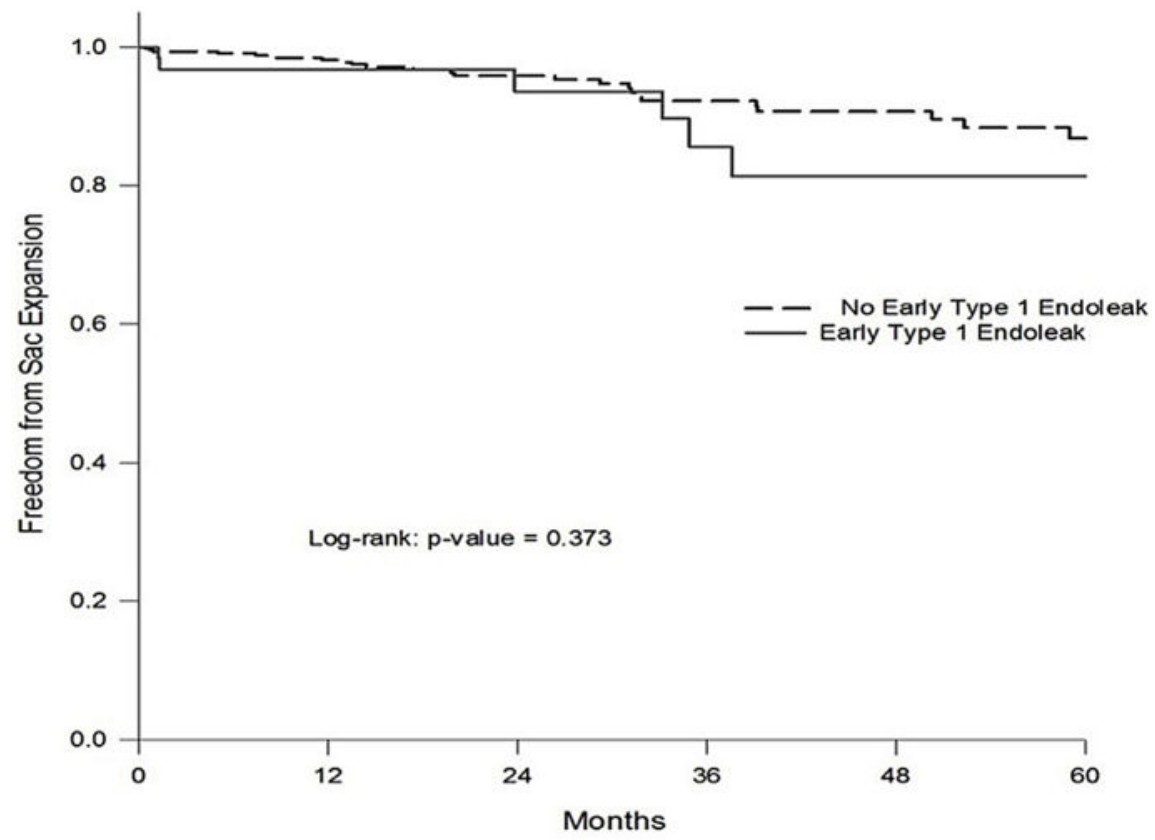

\begin{tabular}{|l|c|c|c|c|c|c|}
\hline \multirow{2}{*}{ Months } & \multicolumn{3}{|c|}{ Early type Ia endoleak (group A) } & \multicolumn{3}{c|}{ No early type Ia endoleak (group B) } \\
\cline { 2 - 7 } & At risk, $\mathbf{n}$ & $\%$ & SE & At risk, n & \% & SE \\
\hline 12 & 48 & 96.8 & 2.25 & 304 & 98.1 & 0.7 \\
\hline 24 & 29 & 93.5 & 3.85 & 193 & 95.8 & 1.17 \\
\hline 36 & 20 & 85.6 & 6.4 & 129 & 92.2 & 1.83 \\
\hline 48 & 15 & 81.3 & 7.4 & 87 & 90.7 & 2.1 \\
\hline 60 & 10 & 81.3 & 7.4 & 54 & 86.8 & 2.99 \\
\hline
\end{tabular}

Figure 3.

Freedom from late sac expansion for groups A and B. 


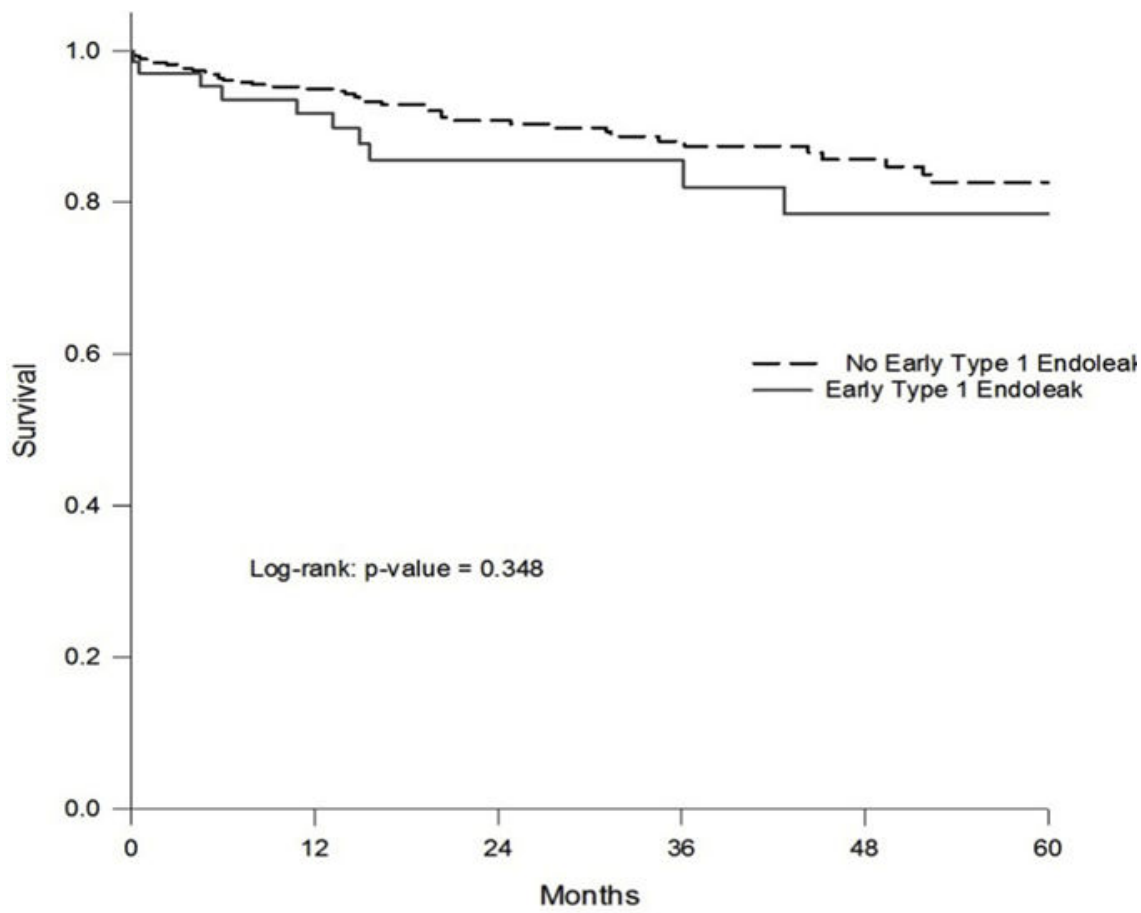

\begin{tabular}{|l|c|c|c|c|c|c|}
\hline \multirow{2}{*}{ Months } & \multicolumn{3}{|c|}{ Early type Ia endoleak (group A) } & \multicolumn{3}{c|}{ No early type Ia endoleak (group B) } \\
\cline { 2 - 7 } & At risk, n & $\%$ & SE & At risk, n & $\%$ & SE \\
\hline 12 & 49 & 91.7 & 3.58 & 308 & 94.9 & 1.11 \\
\hline 24 & 30 & 85.6 & 4.77 & 198 & 90.8 & 1.62 \\
\hline 36 & 24 & 85.6 & 4.77 & 133 & 88.1 & 1.98 \\
\hline 48 & 19 & 78.5 & 6.51 & 92 & 85.7 & 2.36 \\
\hline 60 & 13 & 78.5 & 6.51 & 60 & 82.6 & 2.86 \\
\hline
\end{tabular}

Figure 4.

Survival analysis for groups A and B. 


\section{Table 1}

Demographic and Clinical Characteristics

\begin{tabular}{|c|c|c|c|}
\hline Characteristic & Group A (total $n=71)$ & Group B (total $n=494)$ & p Value \\
\hline Mean age, $y$, (range) & $75.7(48-96)$ & $72.9(45-101)$ & 0.0138 \\
\hline \multicolumn{4}{|l|}{ Age, $\mathrm{y}, \mathrm{n}(\%)$} \\
\hline$<75$ & $30(42)$ & $280(57)$ & 0.0224 \\
\hline$\geq 75$ & $41(58)$ & $214(43)$ & \\
\hline$\geq 80$ & $31(44)$ & $134(27)$ & \\
\hline \multicolumn{4}{|l|}{ Sex, n $(\%)$} \\
\hline Male & $53(75)$ & $408(83)$ & 0.1063 \\
\hline Female & $18(25)$ & $86(17)$ & \\
\hline Hypertension, n (\%) & $60(85)$ & $428(87)$ & 0.6243 \\
\hline COPD, n (\%) & $23(32)$ & $161(33)$ & 0.9736 \\
\hline Tobacco use, n (\%) & $48(68)$ & $308(62)$ & 0.3909 \\
\hline Congestive heart failure, n (\%) & $11(15)$ & $63(13)$ & 0.5223 \\
\hline Stroke/transient ischemic attack, n (\%) & $11(15)$ & $45(9)$ & 0.0923 \\
\hline Atrial fibrillation, $\mathrm{n}(\%)$ & $12(17)$ & $59(12)$ & 0.2386 \\
\hline Coronary artery disease, $\mathrm{n}(\%)$ & $36(51)$ & $294(60)$ & 0.159 \\
\hline Carotid disease, $\mathrm{n}(\%)$ & $6(8)$ & $56(11)$ & 0.467 \\
\hline Peripheral vascular disease, $\mathrm{n}(\%)$ & $7(10)$ & $56(11)$ & 0.7116 \\
\hline Home oxygen, n (\%) & $7(10)$ & $27(5)$ & 0.176 \\
\hline Diabetes, n (\%) & $13(18)$ & $106(21)$ & 0.543 \\
\hline Hyperlipidemia, n (\%) & $44(62)$ & $324(66)$ & 0.55 \\
\hline
\end{tabular}


Table 2

Early and Late Endoleak and Intervention

\begin{tabular}{lccc}
\hline Endoleak/intervention & Group A (total $\mathbf{n}=\mathbf{7 1})^{*}$ & Group B (total n = 494) & p Value \\
\hline Early intervention, $\mathrm{n}(\%)$ & $56(79)$ & $31(6)$ & $<0.0001$ \\
\hline Late type Ia endoleak, $\mathrm{n}(\%)$ & $9(13)^{*}$ & $10(2)$ & $<0.0001$ \\
\hline Sac expansion, $\mathrm{n}(\%)$ & $6(9)^{*}$ & $25(5)$ & 0.2698 \\
\hline Late intervention, $\mathrm{n}(\%)$ & $7(10)^{*}$ & $16(3)$ & 0.0198 \\
\hline Three patients had no late outcome (beyond 30 days). & &
\end{tabular}

